\title{
Методологические подходы к формированию инновационных кластеров в контексте обеспечения сбалансированного регионального развития
}

\author{
Климова Т.Б. ${ }^{18}$, Бондарева Я.Ю. ${ }^{19}$
}

\begin{abstract}
В статье рассматриваются методологические подходы $\kappa$ формированию инновачионных кластеров, как формы, усиливающей взаимосвязанность $u$ взаимодополняемость отраслей в инновачионно-ориентированном пространстве, $в$ контексте обеспечения сбалансированного развития региональной экономики.
\end{abstract}

\section{JEL: 0180}

Ключевые слова: регион, инновационный кластер, инновационная активность, инновационный процесс

На сегодняшний день политика регионального развития в России осуществляется в условиях нарастающих внутрирегиональных диспропорций, изолированности отдельных муниципальных образований от инновационных процессов, обусловленной дефицитом находящихся в их распоряжении инновационных ресурсов. Промышленно развитые регионы показывают устойчиво высокие темпы экономического развития, как правило, за счет опережающего роста нескольких городов. По оценке эксперта Института системного анализа РАН В.Н. Лексина, экономический рост сосредоточен всего в 140 точках из 1027 городов, а также примерно в 152 тыс. сельских населенных пунктов; более 50\% населения страны живет вне зоны экономического роста (Кузьбожев, 2008). Таким образом, расходящийся характер развития муниципальных образований обуславливает необходимость переосмысления подходов к управлению инновационным развитием региональной экономики.

Одним из основных направлений политики инновационного развития регионов является формирование инновационных кластеров.

Кластеры как форма сетевого взаимодействия находят все большее распространение в мире в связи с растущей взаимозависимостью участников инновационного процесса. Кластер - это одна из форм промышленных сетей, обеспечивающая повышение частоты и силы взаимодействия предприятий, в результате возникает дополнительный «общественный капитал», облегчающий доступ к ресурсам. В Финляндии с помощью ряда индикаторов была выявлена степень инновационности компаний, формирующих кластеры, и рассмотрены перспективы развития каждого кластера с учетом проведения кластерной политики. Взяв за основу ромб конкурентных преимуществ М. Портера, были определены сильные и слабые стороны ромба для каждого из кластеров, намечена последовательность улучшения всех детерминант конкурентоспособности, сделан упор на производство товаров и услуг с повышенной добавленной стоимостью.

Государство стимулировало развитие кластеров, гарантируя развитие свободного рынка и создавая специализированные факторы производства с помощью целого комплекса мероприятий: развития рынка труда, системы образования, технопарков и программы центров знаний (Centre of Expertise Programme), транспортной системы, поддержки малого и среднего бизнеса, поощрения использования энергосберегающих технологий и других программ. В итоге в настоящее время, как и было спрогнозировано в 1996 году, наиболее быстрыми темпами развиваются телекоммуникационный, природный и

\footnotetext{
${ }^{18}$ Канд. эконом. наук, доцент Белгородского государственного университета.

${ }^{19}$ Канд. эконом. наук, старший преподаватель Белгородского государственного университета.
} 
здравоохранительный кластер, компании которых в настоящее время являются локомотивами экономики Финляндии.

В США департамент экономического развития, отвечающий за региональную политику, финансирует исследовательские проекты, цель которых - выявление кластеров, и предоставляет специальные гранты отдельным штатам на развитие кластеров, в частности в депрессивных регионах. В настоящий момент стратегия развития практически каждого штата в Америке опирается на развитие кластеров.

Существенную роль в проведении кластерной политики в США играют бизнесассоциации, в частности Национальный совет по конкурентоспособности, в состав которого входят бизнесмены и академики. Иначе говоря, сущность кластера - это развитие эффективных коммуникаций.

Кластеры, будучи межотраслевыми образованиями, усиливают взаимосвязанность, взаимодополняемость отраслей благодаря более быстрому распространению специфических для региона технологий, профессиональных навыков, информации и маркетинга (специфические конкурентные преимущества как бы перетекают через предприятия и отрасли). А это означает ускорение инноваций, что является основой не только для повышения производительности труда, но и для обновления стратегических преимуществ, поддержания динамичной конкуренции.

Кластерный подход позволяет выявить новые возможности повышения производительности труда в промышленности без снижения интенсивности конкуренции.

Инновационный кластер формируют предприятия, являющиеся «полюсами» роста. На наш взгляд, такой подход имеет ограниченное применение для экономики российских регионов со слабо развитой социально-производственной инфраструктурой и не отвечает принципам сбалансированного развития. Введение преференциального режима центров инновационного развития ведет к еще большему усилению региональных диспропорций, причем важную роль играет миграция инновационных ресурсов в «полюсы роста». Политика регионального развития должна быть основана на принципах, обеспечивающих не просто интенсивное развитие «полюсов роста», а позволяющих сформировать устойчивую тенденцию увеличения таких «полюсов социальной и хозяйственной жизни» в результате постепенного встраивания отстающих территорий в инновационную региональную систему.

Решение поставленной задачи тесно увязано с проблемой ресурсного обеспечения инновационных процессов на депрессивных территориях и будет заключаться в том, чтобы из имеющегося множества муниципальных образований выделить те, которые нуждаются в инновационном развитии и не имеют для этого достаточного потенциала, и муниципальные образования, обладающие избыточным инновационным ресурсом. Другими словами, конфигурирование инновационного кластера должно осуществляться на основе анализа инновационного потенциала муниципальных образований и выделения его ресурсной составляющей - финансовой, кадровой или материально-технической. При формировании инновационного кластера необходимо обеспечить движение ресурсных потоков таким образом, чтобы произошло перераспределение ресурсов из места их избыточной концентрации в места, где их не хватает.

Выделенные муниципальные образования, между которыми осуществляется перераспределение ресурсов, формируют так называемый инновационный кластер. Результатом функционирования кластера является значение инновационного потенциала, необходимое для реализации конкретного проекта, обеспечивающего социальноэкономическое развитие конкретной территории без ущерба для тех территорий, за счет которых осуществляется перераспределение ресурсов, и региона в целом.

Принципы выбора муниципальных образований при формировании инновационного кластера могут быть следующими:

- инновационный потенциал муниципального образования полностью обеспечивает реализацию инновационного проекта, отсутствует необходимость привлечения потенциала других муниципальных образований; 
- инновационный потенциал выбранных муниципальных образований дополняет друг друга так, чтобы в целом обеспечивалась возможность реализации инновационного проекта, причем каждое выбранное муниципальное образование в отдельности имеет потенциал, недостаточный для реализации данного проекта;

- в группу муниципальных образований, обладающих высоким инновационным потенциалом, в том числе с избыточным значением показателей по отдельным направлениям, включаются муниципальные образования, обладающие недостаточным потенциалом для инновационного развития.

Таким образом, ресурсное обеспечение реализации инновационного проекта может быть следующим:

- инновационные ресурсы производятся и распределяются внутри одного муниципального образования;

- инновационные ресурсы частично производятся внутри муниципального образования, недостающая часть «ввозится» из других муниципальных образований;

- инновационные ресурсы полностью «ввозятся» из других муниципальных образований.

Основным принципом формирования инновационных кластеров должно быть создание возможностей и способностей всех элементов региональной системы к инновационному виду деятельности. Инновационный кластер должно обеспечивать не столько инновационное развитие отдельных бизнес-единиц, сколько наиболее полное и эффективное включение в процессы регионального воспроизводства ресурсного потенциала территории. При этом в основе инновационного кластера должно находиться интеграционное взаимодействие крупного и малого бизнеса, призванное обеспечить рациональную организацию ресурсных потоков.

Обязательными условиями включения хозяйствующего субъекта в инновационный кластер являются:

- наличие необходимого уровня инновационного потенциала для реализации отраслевых интересов;

- соблюдение интересов регионального развития с позиций обеспечения сбалансированности.

Необходимо отметить, что диспропорции в уровне социально-экономического развития территорий и их инновационного потенциала не являются препятствием к развитию интеграционного взаимодействия между ними, поскольку эффективное использование сильных сторон отдельных муниципальных образований, входящих в кластер, производит дополнительный эффект развития и таким образом способствует региональным процессам роста. Особенно важно, что субъекты инновационной деятельности, находясь в территориальной близости друг от друга, могут формировать взаимодополняющие инфраструктурные элементы, тем самым экономя время на создание собственных. Территории, отличающиеся низким значением социально-экономических показателей, как правило, имеют ресурсы, которые потенциально могут быть использованы в проектах инновационного развития: омертвленный капитал убыточных предприятий; земельные участки, непригодные для сельскохозяйственного использования (Нехаев, 2004). Для постоянного использования преимуществ синергетического эффекта необходимо прилагать значительные усилия по стимулированию интеграционных процессов в региональных системах, укрепляя связи между отдельными муниципальными образованиями. Иными словами, стратегия регионального развития должна формироваться как некоторая сетевая структура, включающая все территориальные образования региона.

Развитие инновационных кластеров позволит интенсифицировать рост конкурентоспособности экономики региона за счет повышения уровня ее диверсификации и получить значительный социально-экономический эффект, в том числе и мультипликативного характера, выражающийся в позитивных тенденциях: стимулирование ускорения темпов роста ВРП; повышение инновационной активности и инвестиционной 
привлекательности региона, формирование новой экономики; диверсификация продукции на внутреннем рынке региона, увеличение доли инновационной продукции.

На сегодняшний день в Белгородской области сформированы следующие кластеры:

1. Горно-металлургический кластер, ядром которого являются: Лебединский (Губкинский городской округ) и Стойленский (Старооскольский городской округ) ГОКи, ведущие добычу железной руды открытым способом, комбинат «КМАруда» (Губкинский городской округ), осуществляющий ее добычу подземным способом, и Оскольский электрометаллургический комбинат (Старооскольский городской округ), машиностроительные предприятия по производственно-ремонтному обеспечению, научные, проектные и учебные заведения.

Главной стратегической задачей горно-металлургического кластера является дальнейшее освоение запасов богатых железных руд и железистых кварцитов Курской магнитной аномалии для производства железорудного сырья высокой металлургической ценности и металлопродукции с более высокой добавленной стоимостью для удовлетворения потребностей области и страны в целом.

2. Кластер по развитию свиноводства, сформированный на основе государственночастного партнерства правительства области с крупными агрохолдингами ГК «АгроБелогорье», ГК «Мираторг», ООО «Белгранкорм», ОАО «Белгородский бекон», которые представляют собой группы технологически взаимосвязанных компаний с замкнутым циклом, использующие современные зарубежные и отечественные инновационные технологии и генетические материалы. Предприятия кластера расположены на территории 15 районов области.

3. Кластер по развитию птицеводства, сформированный на основе государственночастного партнерства правительства области и крупных агрохолдингов: ЗАО «Приосколье», ЗАО «Краснояружский бройлер», ЗАО «Белая птица», ООО «БЭЗРК-Белгранкорм», ООО «Белгород-семена». Предприятия кластера расположены на территориях 17 районов области.

4. Кластер по развитию молочного животноводства, сформированный на основе государственно-частного партнерства правительства области и таких крупных агрохолдингов, как ООО «ГК «Агро-Белогорье», ОАО «Белгородские молочные фермы», ЗАО «Оскольское молоко», ООО «Агрохолдинг «Авида», ОАО «Молоко Белогорья», использующих современные зарубежные и отечественные инновационные технологии. Предприятия кластера по развитию молочного животноводства расположены на территории 19 муниципальных районов и одного1 городского округа области.

5. Строительный кластер, реализующий в области масштабное строительство жилья, особенно индивидуального, стал своего рода катализатором для создания и дальнейшего развития кластера в строительстве. В состав кластера входят предприятия стройиндустрии, использующие высокоэффективные, инновационные технологии, научные, образовательные, проектно-изыскательские организации, подрядные организации, а также организации, оказывающие государственную поддержку жилищного строительства.

6. Мультимодальная приграничная транспортно-логистическая зона. Транспортнологистическая зона будет включать сопутствующую логистическую среду и инфраструктуру: таможенные терминалы, автомобильные и железнодорожные скоростные линии, складские комплексы и контейнерные терминалы, сеть супермаркетов, гостиничный комплекс, приграничный выставочный комплекс, деловой центр, автопаркинг и другие объекты.

7. Инновационный кластер, сформированный на основе построения инновационной инфраструктуры в городах Белгород и Старый Оскол, обуславливает необходимость выделения отдельно инновационного кластера. В инновационную деятельность активно включаются Белгородский государственный университет, Белгородский государственный технологический университет им. В.Г. Шухова, Белгородская сельскохозяйственная академия, Центр нанотехнологий, технопарки и бизнес-инкубаторы при высших учебных заведениях.

Региональные органы государственной власти должны сделать все необходимое, чтобы 
ускорить развитие кластеров и превратить их в источник долгосрочного экономического роста. Улучшая условия развития кластера, государственные органы управления действуют одновременно в интересах многих предприятий региона. Кластеризация экономики региона будет означать создание источника долгосрочного экономического роста.

Формирование инновационных кластеров в соответствии с предлагаемыми принципами позволяет решить проблему сбалансированного регионального развития, обеспечив включение территорий с низким уровнем развития в инновационные процессы, позволяет выявить возможные перспективы развития региона, направления усиления его инновационного потенциала.

\section{Список литературы}

1. Кузьбожев Э.Н., Смирнов М.А. Модель исследования комплексности систем // Экономический анализ: теория и практика. 2008. № 14(119). С. 31-35.

2. Нехаев С.А. Формирование программ социально-экономического развития регионов России в условиях глобализации мировой экономики // Финансы.ru: интернет-журнал. 30.09.04. URL: http://www.finansy.ru/publ/tax/003.htm. 